\title{
Mood Stabilizers and the Influence on Global Leukocyte DNA Methylation in Bipolar Disorder
}

\author{
Lena Backlund ${ }^{b, d}$, e Ya Bin Wei ${ }^{b, e} \quad$ Lina Martinsson ${ }^{a, b} \quad$ Philippe A. Melas ${ }^{a}$ e \\ Jia Jia Liu ${ }^{b, e, f}$ Ninni Mub, e Claes-Göran Östenson ${ }^{c}$ Tomas J. Ekström ${ }^{\text {a, e }}$ \\ Martin Schalling ${ }^{\text {b, e }}$ Catharina Lavebratt ${ }^{\text {b, e }}$ \\ ${ }^{a}$ Department of Clinical Neuroscience, and ${ }^{b}$ Neurogenetics Unit and ${ }^{\mathrm{C} E n d o c r i n e}$ and Diabetes Unit, Department \\ of Molecular Medicine and Surgery, Karolinska Institutet, ${ }^{\mathrm{d} C e n t r e}$ for Psychiatric Research and Education, and

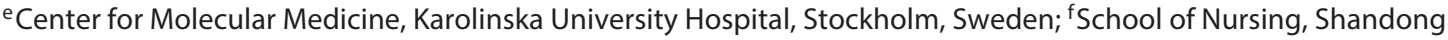 \\ University, Jinan, China
}

\section{Key Words}

Bipolar disorder · DNA methylation · Lithium · Valproate · Antipsychotics

\begin{abstract}
Little is known about the relationship between treatments for bipolar disorder (BD), their therapeutic responses and the DNA methylation status. We investigated whether global DNA methylation levels differ between healthy controls and bipolar patients under different treatments. Global DNA methylation was measured in leukocyte DNA from bipolar patients under lithium monotherapy $(n=29)$ or combination therapy ( $n=32$ ) and from healthy controls $(n=26)$. Lithium response was assessed using the Alda scale. Lithium in monotherapy was associated with hypomethylation $(\mathrm{F}=$ $4.63, p=0.036)$. Lithium + valproate showed a hypermethylated pattern compared to lithium alone $(F=7.27, p=0.011)$. Lithium response was not associated with DNA methylation levels. These data suggest that the choice of treatment in BD may lead to different levels of global DNA methylation. However, further research is needed to understand its clinical significance.

(c) 2015 S. Karger AG, Basel
\end{abstract}

(c) 2015 S. Karger AG, Base

2296-9209/15/0012-0076\$39.50/0

\section{Introduction}

Bipolar disorder (BD) is a severe and chronic psychiatric disorder that is characterized by episodes of mania and depression. The main strategy in the treatment of $\mathrm{BD}$ is to prevent new episodes of illness. The usage of lithium (Li) as a long-term mood stabilizer is established as firstline maintenance treatment [1]. Li with another mood stabilizer in combination, valproate (VPA), for the prevention of episodes, has increased in recent years and there is also good evidence supporting the usage of Li with antipsychotic drugs in combination, for more treatmentresistant bipolar patients [2].

The concordance rate of BD in monozygotic twins has been estimated to be $40-70 \%$, which indicates that genes alone do not account for the etiology of the disorder [3]. It has been proposed that a part of this 'missing heritability' in BD may be accounted for by epigenetic modifications [4]. The term 'epigenetics' is broadly used to describe mechanisms and molecular marks, like DNA methylation and histone modifications, that affect gene expression without altering the DNA sequence itself [5, 6]. There is emerging evidence suggesting that different

\section{KARGER 125}

E-Mail karger@karger.com www.karger.com/mnp
Dr. Lena Backlund

Center of Affective Disorder

Northern Stockholm Psychiatry

Vardvagen 3, SE-112 81 Stockholm (Sweden)

E-Mail lena.backlund@ki.se 
Table 1. Clinical characteristics of the study groups

\begin{tabular}{|c|c|c|c|c|c|}
\hline \multicolumn{2}{|c|}{ Group } & \multirow{2}{*}{$\begin{array}{l}\mathrm{n} \\
29\end{array}$} & \multirow{2}{*}{$\begin{array}{l}\text { Males, \% } \\
41.4\end{array}$} & \multirow{2}{*}{$\begin{array}{l}\text { Age, years } \\
59(38,63) 26-77\end{array}$} & \multirow{2}{*}{$\begin{array}{l}\text { Global DNA methylation level } \\
1.09 \pm 0.07^{\mathrm{a}}\end{array}$} \\
\hline I & Li-mono & & & & \\
\hline II & $\mathrm{Li}+\mathrm{VPA}$ & 11 & 27.3 & $56(43,61) 39-72$ & $1.58 \pm 0.25^{\mathrm{b}}$ \\
\hline & $\mathrm{Li}+$ antipsychotics & 21 & 23.8 & $39(30,48) 23-68^{c}$ & $1.41 \pm 0.16$ \\
\hline IV & healthy control & 26 & 31.0 & $48(38,64) 37-59$ & $1.28 \pm 0.06$ \\
\hline
\end{tabular}

Males: the gender distribution is not statistically different between groups tested using Pearson's $\chi^{2}$ test, $\mathrm{p}=$ 0.66. Age: median (25th, 75 th percentiles) range. Global DNA methylation level: relative value, mean \pm 1 standard error of the mean. ${ }^{\mathrm{a}} \mathrm{p}<0.05$, compared with healthy controls using ANCOVA adjusted for age and $\operatorname{sex} ;{ }^{\mathrm{b}} \mathrm{p}<0.05$, compared with group I using ANCOVA adjusted for age and sex; ${ }^{c} \mathrm{p}<0.05$, compared with group I after Bonferroni correction.

environmental stimuli, including exposure to drugs, may affect the epigenome. For example, VPA is known to act as a histone deacetylase inhibitor (HDACi) that may affect both histone and nonhistone marks, and there is a strong link between histone modifications and DNA methylation [7]. VPA treatment of mice at possible therapeutic concentrations showed a hypomethylating effect in the brain on Reelin and Gad67 promoters $[8,9]$. The VPA effect on methylation of other genes in animals is unfortunately unknown. The HDACi effect of VPA was present for $\mathrm{H} 3$ but not $\mathrm{H} 4$ [10].

Some previous in vitro studies in neuroblastoma cell lines suggested that VPA treatment is associated with global hypermethylation [11-13]. Further, Huzayyin et al. [14] reported decreased global methylation in lymphoblast cell lines from lithium-treated bipolar patients who responded well to Li compared to healthy controls.

In the present study we investigated global DNA methylation in leukocytes from bipolar patients with different pharmacological maintenance treatments.

\section{Material and Methods}

A cohort $(n=256)$ with the clinical diagnosis of BD on Li medication was recruited from the Unit of Affective Disorders at Psychiatry Southwest, in Stockholm, Sweden. Lifetime manic and depressive symptoms were assessed by a trained psychiatric nurse using the modules for mania and depression in the Schedules for Clinical Assessment in Neuropsychiatry, as previously described [15]. Li response was then measured according to the Retrospective Criteria of Long-Term Treatment Response in Research Subjects with Bipolar Disorder (Alda scale), considering the reduction of bipolar symptoms after the beginning of Li treatment (criterion A, range 1-10), adjusted for known confounders, the number of episodes before/off the treatment (B1), the frequency of episodes before/off the treatment (B2), the duration of Li treatment with serum concentrations of $0.5-0.9 \mathrm{mmol} / \mathrm{l}$ (B3), the compliance dur-

Influence of Mood Stabilizers on Globa Leukocyte DNA Methylation in BD ing period(s) of stability (B4), and the use of additional medication during periods of stability (B5). The sum of B scores (B1-B5) was then subtracted from the A score [16].

From this cohort, all those with a therapeutic lithium serum concentration during at least 3 months that were under lithium monotherapy (Li-mono; group I) or Li therapy in combination with either VPA (group II) or neuroleptic drugs (group III) were selected. Because smoking has been reported to influence DNA methylation [17] and in a preliminary analysis of BD $(n=96)$ we found smoking to associate with higher levels of leukocyte methylation, only patients being nonsmokers during the year before sampling were finally included in the study $(n=64)$. Nonsmoking, normal-weight (BMI 20-25), healthy controls (group IV), age- and gender-matched to the combined BD groups (I-III), were selected from well-characterized healthy individuals from the Stockholm Diabetes Prevention Program at the Karolinska University Hospital [18]. Clinical characteristics of the subjects that were successfully profiled for DNA methylation levels are shown in table 1.

\section{Global DNA Methylation}

DNA from peripheral blood samples was extracted using a sodium dodecylsulfate-urea and phenol/chloroform/isoamylalcohol procedure, as previously described [19]. Global DNA methylation levels were measured with the 5-mC DNA ELISA Kit (Zymo Research Corporation, Irvine, Calif., USA), a method used for the quantification of global DNA methylation which utilizes 5-mC antibodies that bind specifically to methylated sites of the genome. In brief, DNA samples ( 100 ng), processed in duplicates, were denatured at $98^{\circ} \mathrm{C}$ for $5 \mathrm{~min}$. After cooling down, denatured DNA was coated in ELISA plates at $37^{\circ} \mathrm{C}$ for $1 \mathrm{~h}$. Then the plates were washed several times followed by blocking at $37^{\circ} \mathrm{C}$ for $30 \mathrm{~min}$. An antibody against $5-\mathrm{mC}$ was incubated at $37^{\circ}$ for 1 $\mathrm{h}$ followed by washing and developing steps. The absorbance was measured at $405 \mathrm{~nm}$ using an ELISA plate reader. Two identical samples were included in each plate for interplate calibration, and a standard curve (including 5-mC levels of $0,10,25,50,75$ and $100 \%$ ) was generated in each plate for calculating methylation levels and monitoring the efficiency. Relative values were calculated by normalizing the mean methylation values from each sample to the same interplate calibrator. DNA samples with a standard deviation of $>0.1$ between duplicates were omitted from the analyses $(\mathrm{n}=3)$. 
Statistical Analyses

Differences in clinical characteristics between study groups were assessed using Pearson's $\chi^{2}$ test or Kruskal-Wallis test. Dependence of global DNA methylation on VPA and antipsychotic treatment was assessed using analysis of covariance (ANCOVA) after adjusting for age and sex. A p value of $<0.05$ was regarded as statistically significant. The analyses were performed using IBM SPSS Statistics version 22 (IBM Corporation, Armonk, N.Y., USA).

\section{Results}

\section{Bipolar Patients under Lithium Monotherapy Had} Reduced Leukocyte DNA Methylation

Global DNA methylation levels were not statistically different between all bipolar patients (combined groups I, II and III) and healthy controls, after adjusting for age and sex (BD vs. controls: $\mathrm{F}=0.001, \mathrm{p}=0.97$; age: $\mathrm{F}=1.60$, $\mathrm{p}=0.21$; sex: $\mathrm{F}=3.32, \mathrm{p}=0.072$; ANCOVA). However, there was a difference in distribution of methylation level between the 4 groups $(\mathrm{F}=3.35$, d.f. $=3, \mathrm{p}=0.023$; age: $\mathrm{p}=0.42$; sex: $\mathrm{p}=0.016$; ANCOVA). Li-mono had a lower DNA methylation level than controls $(\mathrm{F}=4.63, \mathrm{p}=0.036$; age: $\mathrm{p}=0.76$; sex: $\mathrm{p}=0.70$; ANCOVA, fig. 1 ). We did not find a relationship between methylation and Alda score at sampling $(\mathrm{p}>0.05)$.

\section{VPA Treatment Was Associated with DNA \\ Hypermethylation in Bipolar Patients}

Several findings have shown that VPA affects DNA methylation in vitro [13]. We tested whether VPA treatment influenced the DNA methylation levels in bipolar patients by comparing group I (Li-mono) and group II ( $\mathrm{Li}$ + VPA). The bipolar patients under both Li and VPA treatment had significantly higher DNA methylation levels compared to the Li-mono group, after adjusting for age and sex ( $\mathrm{Li}+\mathrm{VPA}$ vs. Li-mono: $\mathrm{F}=7.27, \mathrm{p}=0.011$; age: $p=0.57$; sex: $p=0.39$; ANCOVA).

\section{Trend for DNA Hypermethylation in Bipolar Patients on Antipsychotic Treatment}

Next, we tested if neuroleptic drugs influenced the DNA methylation levels in BD. By comparing group I (Limono) with group III ( $\mathrm{Li}+$ antipsychotics), we found a trend for increased DNA methylation levels in the patients under a combination treatment with $\mathrm{Li}$ and antipsychotics compared to those under Li monotherapy. However, this difference was not statistically significant after adjusting for age and sex $(\mathrm{Li}+$ antipsychotics vs. $\mathrm{Li}$ mono: $\mathrm{F}=3.4, \mathrm{p}=0.071$; age: $\mathrm{p}=0.56$; sex: $\mathrm{p}=0.17$; $\mathrm{AN}-$ COVA).

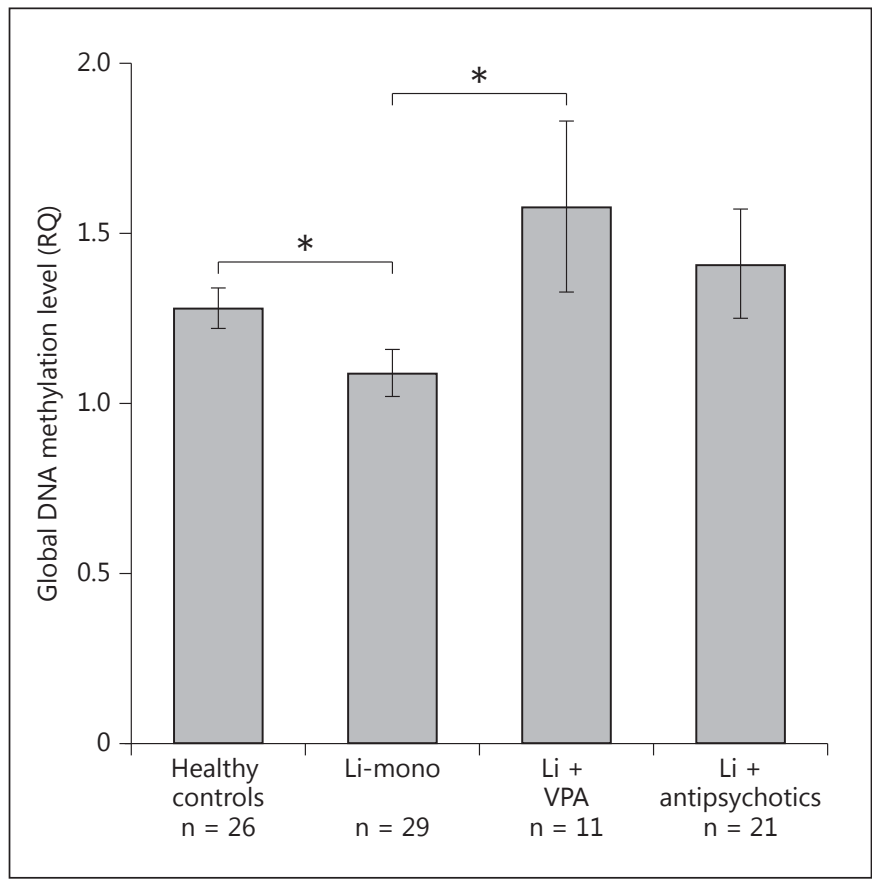

Fig. 1. Global DNA methylation levels $(5-\mathrm{mC})$ were significantly increased in BD patients on $\mathrm{Li}+\mathrm{VPA}$ (group II) compared to patients on Li-mono (group I). A trend for hypermethylation was also present in $\mathrm{BD}$ patients treated with $\mathrm{Li}+$ antipsychotics (group III), although it was not statistically significant compared to group I. The $\mathrm{y}$-axis represents 5 - $\mathrm{mC}$ relative quantity (RQ) values. Bars indicate group means \pm SEM. ${ }^{*} \mathrm{p}<0.05$.

\section{Discussion}

To our knowledge, this is the first study to examine the relationship in bipolar patients between global DNA methylation levels and treatment with different mood stabilizers used in $\mathrm{BD}$. We found that patients under $\mathrm{Li}$ monotherapy displayed lower levels of global leukocyte methylation compared to healthy controls. However, we did not find a relationship between methylation and $\mathrm{Li}$ response. Bipolar patients on Li and VPA in combination displayed higher levels of global DNA methylation compared to patients under Li monotherapy.

Our finding that bipolar patients with Li monotherapy had leukocyte hypomethylation could suggest that $\mathrm{Li}$ causes corresponding epigenetic changes in the brain of the same individuals. Lithium's neuroprotective effects are partly mediated by the inhibition of glycogen synthase kinase $3 \beta$ that promotes cell survival and protects the brain during toxic exposure [20]. A new finding has shown that inhibition of glycogen synthase kinase $3 \beta$ in DOI: $10.1159 / 000430867$
Backlund/Wei/Martinsson/Melas/Liu/Mu/ Östenson/Ekström/Schalling/Lavebratt 
stem and germ cells leads to pronounced reduction of DNA methylation [21], which strengthens the suggestion that $\mathrm{Li}$ may have epigenetic effects that underlie the mechanisms leading to hypomethylation, but in this previous study there were only bipolar patients with a good Li response [14].

The fact that global DNA methylation levels did not differ when comparing all the bipolar patients overall with healthy controls could be explained by the groups who had Li in combination with antipsychotics or VPA. VPA is known to act as a HDACi [22]. In addition, there are in vitro studies suggesting that VPA may lead to altered DNA methylation [23], which may be a consequence of the strong link between histone modifications and DNA methylation [7]. In neuroblastoma cell lines, VPA had the potential to lead to both hypermethylation and hypomethylation at specific gene sites, with a tendency to an overall shift towards hypermethylation [13]. Similarly, VPA increased global DNA methylation in neuroblastoma cell lines. In accordance with these data, we found that bipolar patients on both Li and VPA were hypermethylated compared to those on Li monotherapy.

In schizophrenia studies, it was found that patients on neuroleptic drugs may display higher global DNA methylation levels compared to those without neuroleptic drugs [24-26]. In the bipolar patients whom we examined, we observed a tendency $(\mathrm{p}=0.07)$ towards higher levels of global DNA methylation in those on both $\mathrm{Li}$ and antipsychotics compared to patients under Li monotherapy.

Although the role of epigenetics in BD has been studied in recent years and gained support, very few studies have examined the relationship between treatments in psychiatric disorders, their therapeutic responses and the DNA methylation status of the patients [14, 27, 28]. Our first finding indicates that global DNA methylation levels are not altered in the leukocytes of BD patients overall, which is in line with what has been previously reported [29]. However, the DNA methylation levels in leukocytes may not necessarily reflect the molecular changes found in the brains of patients with neuropsychiatric disorders. For instance, there is one postmortem study that found increased global DNA methylation in the frontal cortex of bipolar patients [30]. Nevertheless, using more accessible organs, like blood, allows for the molecular monitoring of living patients and the study of drug-epigenome interactions similar to the ones indicated by the present report. Further, our data are in line with the recent study that showed that $\mathrm{Li}$ response was associated with hypomethylation compared to healthy individuals [14]. How-

Influence of Mood Stabilizers on Global Leukocyte DNA Methylation in BD ever, that study did only investigate good Li responders. And they did not compare DNA methylation in Li responders to other Li-treated bipolar patients. When doing the same analysis in both Li responders and nonresponders in our study, and according to the Alda scale, we could not find such an association. Thus, lithium's epigenetic effects may be independent of Li response.

When conducting epigenetic psychopharmacological studies, it is also important to consider the confounding effects of nonmedicinal substances known to affect the epigenome. For example, there is evidence that smoking may cause gene-specific hypermethylation or overexpression of DNA methyltransferases $[17,31]$ through e.g. smoking-induced DNA damage and hypoxia with downstream effects on enzyme activation and gene transcription [32]. In line with these data, we found that smokers displayed a significantly higher level of global DNA methylation compared to nonsmokers, and due to the retrospective design we excluded smokers from the study. When interpreting the results, one should also have in mind that all the patients were sampled in their euthymic state. This might affect the outcome, since the expression of DNA methyltransferases in white blood cells has been shown to vary depending on which state the patients are in [33].

Strengths of this study include: (i) the method used for quantification of global DNA methylation utilizes 5-mC antibodies that bind specifically to methylated sites of the genome, providing specificity compared to DNA methylation methods based on bisulfite conversion that cannot distinguish between DNA methylation and hydroxymethylation [34]; (ii) when analyzing the effects of treatment, we corrected for the interactive effects of different drugs, which is of importance since combination therapy in $\mathrm{BD}$ is very common and previous studies of DNA methylation in $\mathrm{BD}$ have not examined the interaction between drugs [29], and (iii) this study is the first to measure Li response based on a specific continuous scale (the Alda scale) which takes into consideration well-known confounders, such as severity before and after treatment, duration of illness before Li treatment and the number of episodes before treatment [16].

Even if our results provide putatively novel insights into the link between BD treatments and DNA methylation, these data should be regarded as exploratory given some main limitations in this study: (i) the sample size was rather small; (ii) we used a surrogate tissue (leukocytes) which may not mirror DNA methylation changes in the brain; (iii) alcohol, substance abuse and comorbidities may have an impact on DNA methylation pat- 
terns $[17,35]$ but could not be taken into consideration due to a lack of such information; (iv) there were no patients on VPA or antipsychotics in monotherapy; (v) due to the small sample size we could not compare the effect of separate antipsychotics on DNA methylation, and (vi) we cannot exclude the possibility that the identified differential methylation level was due to differential leukocyte profiles. We did not have access to the distribution of leukocyte types. However, the DNA hypomethylation in bipolar patients with $\mathrm{Li}$ in monotherapy is in line with the previous finding of DNA hypomethylation in transformed lymphoblasts from Li responders [14]. There is only one study about VPA's effect on leukocyte distribution, in which VPA was associated with a similarly sized (5\%) reduction in neutrophils and in CD4+ lymphocytes [36].

Although epigenetic changes have been implicated in the etiology of psychiatric disorders [4], little is known about the epigenetic components of $\mathrm{BD}$ and the epigenetic influences of medications used in the treatment of the disorder. Findings of the present study imply that the usage of mood stabilizers may lead to systemic epigenetic effects. This study does not examine the molecular mechanisms that link epigenetics with BD pathophysiology, but its findings may still be of importance in future clinical practices since there is a high demand for biomarkers of treatment response in $\mathrm{BD}$. However, in order to find biomarkers for $\mathrm{BD}$, a more comprehensive understanding of the molecular mechanisms behind this observation is needed. In future studies, it is also important to assess the effects of separate mood stabilizers on global DNA methylation prospectively in larger cohorts conducted on drug-naive bipolar patients in the euthymic state before and after medication.

\section{Acknowledgments}

We thank Inger Römer Ek, RN, MSc, for the phenotyping of the bipolar patients. The project was supported by grants from Karolinska Institutet, the Swedish Research Council, the Söderström-Königska Foundation, the AFA Insurance and the regional agreement on medical training and clinical research (ALF) between Stockholm County Council and Karolinska Institutet. We also want to thank the patients who participated in this study.

\section{Statement of Ethics}

The study was approved by the Regional Ethical Review Board in Stockholm, Sweden, in accordance with the Helsinki Declaration of 1975. Both written and verbal informed consent was obtained by a specialized psychiatric nurse at a visit in the euthymic state. All individuals had full capacity to consent. The procedure was documented in the research protocol, fulfilling the Swedish legal requirements.

\section{Disclosure Statement}

None of the authors had any disclosures to declare.

\section{References}

1 Licht RW: Lithium: still a major option in the management of bipolar disorder. CNS Neurosci Ther 2012;18:219-226.

2 Geddes JR, Miklowitz DJ: Treatment of bipolar disorder. Lancet 2013;381:1672-1682.

3 Craddock N, Sklar P: Genetics of bipolar disorder. Lancet 2013;381:1654-1662.

4 Petronis A: Epigenetics and bipolar disorder: new opportunities and challenges. Am J Med Genet Part C Semin Med Genet 2003;123:c65c75.

5 Ekstrom TJ: Epigenetic control of gene expression. Biochim Biophys Acta 2009;1790: 845-846.

6 Jaenisch R, Bird A: Epigenetic regulation of gene expression: how the genome integrates intrinsic and environmental signals. Nat Genet 2003;33(suppl):245-254.

7 Cedar H, Bergman Y: Linking DNA methylation and histone modification: patterns and paradigms. Nat Rev Genet 2009;10:295-304.
8 Tremolizzo L, Carboni G, Ruzicka WB, Mitchell CP, Sugaya I, Tueting P, Sharma R, Grayson DR, Costa E, Guidotti A: An epigenetic mouse model for molecular and behavioral neuropathologies related to schizophrenia vulnerability. Proc Natl Acad Sci USA 2002;99:17095-17100.

\9 Dong E, Agis-Balboa RC, Simonini MV, Grayson DR, Costa E, Guidotti A: Reelin and glutamic acid decarboxylase67 promoter remodeling in an epigenetic methionine-induced mouse model of schizophrenia. Proc Natl Acad Sci USA 2005;102:12578-12583.

10 Dong E, Chen Y, Gavin DP, Grayson DR, Guidotti A: Valproate induces DNA demethylation in nuclear extracts from adult mouse brain. Epigenetics 2010;5:730-735.

-11 Gu S, Tian Y, Chlenski A, Salwen HR, Lu Z, Raj JU, Yang Q: Valproic acid shows a potent antitumor effect with alteration of DNA methylation in neuroblastoma. Anticancer Drugs 2012;23:1054-1066.
12 Milutinovic S, D’Alessio AC, Detich N, Szyf M: Valproate induces widespread epigenetic reprogramming which involves demethylation of specific genes. Carcinogenesis 2007; 28:560-571.

-13 Asai T, Bundo M, Sugawara H, Sunaga F, Ueda J, Tanaka G, Ishigooka J, Kasai K, Kato T, Iwamoto K: Effect of mood stabilizers on DNA methylation in human neuroblastoma cells. Int J Neuropsychopharmacol 2013;16: 2285-2294.

$\checkmark 14$ Huzayyin AA, Andreazza AC, Turecki G Cruceanu C, Rouleau GA, Alda M, Young LT: Decreased global methylation in patients with bipolar disorder who respond to lithium. Int J Neuropsychopharmacol 2014;17:561-569.

15 Backlund L, Lavebratt C, Frisen L, Nikamo P, Hukic Sudic D, Traskman-Bendz L, Landen M, Edman G, Vawter MP, Osby U, Schalling M: P2RX7 expression responds to sleep deprivation and associates with rapid cycling in bipolar disorder type 1. PloS One 2012;7:e43057. 
16 Grof P, Duffy A, Cavazzoni P, Grof E, Garnham J, MacDougall M, O'Donovan C, Alda M: Is response to prophylactic lithium a familial trait? J Clin Psychiatry 2002;63:942947.

17 Alegria-Torres JA, Baccarelli A, Bollati V: Epigenetics and lifestyle. Epigenomics 2011;3: 267-277.

18 Almgren M, Atkinson R, He J, Hilding A, Hagman E, Wolk A, Thorell A, Marcus C, Naslund E, Ostenson CG, Schalling M, Lavebratt C: Adenovirus-36 is associated with obesity in children and adults in Sweden as determined by rapid ELISA. PLoS One 2012 7:e41652.

19 Martinsson L, Wei Y, Xu D, Melas PA, Mathe AA, Schalling M, Lavebratt C, Backlund L: Long-term lithium treatment in bipolar disorder is associated with longer leukocyte telomeres. Transl Psychiatry 2013;3:e261.

20 Jope RS: Glycogen synthase kinase-3 in the etiology and treatment of mood disorders. Front Mol Neurosci 2011;4:16.

-21 Leitch HG, McEwen KR, Turp A, Encheva V, Carroll T, Grabole N, Mansfield W, Nashun B, Knezovich JG, Smith A, Surani MA, Hajkova $P$ : Naive pluripotency is associated with global DNA hypomethylation. Nat Struct Mol Biol 2013;20:311-316.

22 Boyadjieva N, Varadinova M: Epigenetics of psychoactive drugs. J Pharm Pharmacol 2012; 64:1349-1358.
3 Gu JX, Wei MY, Rao PH, Lau CC, Behl S, Man TK: CGI: Java software for mapping and visualizing data from array-based comparative genomic hybridization and expression profiling. Gene Regul Systems Biol 2007;1:131-136.

24 Melas PA, Rogdaki M, Osby U, Schalling M, Lavebratt C, Ekstrom TJ: Epigenetic aberrations in leukocytes of patients with schizophrenia: association. FASEB J 2012;26:2712-2718.

25 Bonsch D, Wunschel M, Lenz B, Janssen G, Weisbrod M, Sauer H: Methylation matters? Decreased methylation status of genomic DNA in the blood of schizophrenic twins. Psychiatry Res 2012;198:533-537.

26 Shimabukuro M, Jinno Y, Fuke C, Okazaki Y: Haloperidol treatment induces tissue- and sex-specific changes in DNA methylation: a control study using rats. Behav Brain Funct 2006;2:37.

27 Domschke K, Tidow N, Schwarte K, Ziegler C, Lesch KP, Deckert J, Arolt V, Zwanzger P, Baune BT: Pharmacoepigenetics of depression: no major influence of MAO-A DNA methylation on treatment response. J Neural Transm 2015;122:99-108.

28 Tang H, Dalton CF, Srisawat U, Zhang ZJ, Reynolds GP: Methylation at a transcription factor-binding site on the 5-HT1A receptor gene correlates with negative symptom treatment response in first episode schizophrenia. Int J Neuropsychopharmacol 2014;17:645649.

29 Bromberg A, Bersudsky Y, Levine J, Agam G: Global leukocyte DNA methylation is not altered in euthymic bipolar patients. J Affect Disord 2009;118:234-239.
30 Rao JS, Keleshian VL, Klein S, Rapoport SI: Epigenetic modifications in frontal cortex from Alzheimer's disease and bipolar disorder patients. Transl Psychiatry 2012;2:e132.

31 Lin RK, Hsu HS, Chang JW, Chen CY, Chen JT, Wang YC: Alteration of DNA methyltransferases contributes to $5^{\prime} \mathrm{CpG}$ methylation and poor prognosis in lung cancer. Lung Cancer 2007;55:205-213.

32 Lee KW, Pausova Z: Cigarette smoking and DNA methylation. Front Genet 2013;4:132.

33 Higuchi F, Uchida S, Yamagata H, Otsuki K, Hobara T, Abe N, Shibata T, Watanabe Y: State-dependent changes in the expression of DNA methyltransferases in mood disorder patients. J Psychiatr Res 2011;45:1295-1300.

-34 Huang Y, Pastor WA, Shen Y, Tahiliani M, Liu DR, Rao A: The behaviour of 5-hydroxymethylcytosine in bisulfite sequencing. PLoS One 2010;5:e8888.

35 Guidotti A, Dong E, Gavin DP, Veldic M, Zhao W, Bhaumik DK, Pandey SC, Grayson DR: DNA methylation/demethylation network expression in psychotic patients with a history of alcohol abuse. Alcohol Clin Exp Res 2013;37:417-424.

36 Guenther S, Bauer S, Hagge M, Knake S, Olmes DG, Tackenberg B, Rosenow F, Hamer HM: Chronic valproate or levetiracetam treatment does not influence cytokine levels in humans. Seizure 2014;23:666-669. 